Enferm Bras 2021;20(6):750-63

doi: $\underline{10.33233 / e b . v 20 i 6.4740}$

\title{
ARTIGO ORIGINAL \\ Uso do blog como ferramenta de educação em saúde para pais e familiares de crianças
}

Sara Rodrigues Rosado, D.Sc.*, Adriana Gomes Mateus Leite**, Cibele Dias Evangelista Braga**, Claudirene Milagres Araújo, M.Sc. ${ }^{* *}$, Patrícia Eliza Miranda Dupim $^{\star * *}$, Samara Macedo Cordeiro, D.Sc. ${ }^{* * *}$, Camille Graziele da Silva Alves ${ }^{* * * *}$

*Enfermeira, Docente do Curso de Enfermagem da Universidade São Judas Tadeu (USJT), São Paulo, SP, ${ }^{* *}$ Graduada em Enfermagem pelo Centro Universitário de Belo Horizonte (UniBH), Belo Horizonte, MG, ${ }^{* * * E n f e r m e i r a, ~ D o c e n t e ~ d o ~ C u r s o ~ d e ~}$ Enfermagem do UniBH, Belo Horizonte, MG, ${ }^{* * *}$ Enfermeira, Docente do Curso de Enfermagem da Faculdade de Ciências Médicas da Santa Casa de São Paulo, São Paulo, SP, ${ }^{* * * * E n f e r m e i r a ~ p e l a ~ F a c u l d a d e ~ d e ~ C i e ̂ n c i a s ~ M e ́ d i c a s ~ d a ~ S a n t a ~ C a s a ~ d e ~ S a ̃ o ~}$ Paulo, São Paulo, SP

Recebido em 19 de abril de 2021; Aceito em 2 de novembro de 2021.

Correspondência: Sara Rodrigues Rosado, Rua Jaci, 90/72 Chácara Inglesa 04140080 São Paulo SP

Sara Rodrigues Rosado: sara.rrosado@hotmail.com Adriana Gomes Mateus Leite: adrianaleitemateus@gmail.com Cibele Dias Evangelista Braga: cibelediasev@hotmail.com Claudirene Milagres Araújo: claudirene.araujo@prof.unibh.br Patrícia Eliza Miranda Dupim: patríciaelizamiranda@gmail.com Samara Macedo Cordeiro: samaramacedocordeiro@yahoo.com.br Camille Graziele da Silva Alves: camille.grazz@gmail.com

\section{Resumo}

Objetivo: Descrever a experiência da elaboração de um blog como ferramenta de comunicação em saúde para mães, pais e familiares cuidadores de crianças no seu primeiro ano de vida. Métodos: Estudo descritivo, do tipo relato de experiência sobre a elaboração de uma ferramenta de educação em saúde online. Para sua elaboração e desenvolvimento, foram contempladas sete etapas: diagnóstico situacional; revisão de literatura; elaboração e construção do blog; validação de conteúdo; publicidade e divulgação do blog; atualização das postagens e interação com os internautas; análise 
das participações. Resultados: O blog foi dividido em postagens, seguindo as temáticas sobre aleitamento materno, higiene, vacinação, introdução de alimentos e etapas do desenvolvimento da criança. Conclusão: O blog favorece o desenvolvimento de habilidades para os cuidados com o bebê por contemplar informações com qualidade, ilustrações e linguagem simples, sanar dúvidas através de fórum e promover autonomia dos pais nos cuidados do seu bebê.

Palavras-chave: blogs; criança; educação em saúde; pais.

\section{Abstract}

\section{Use of the blog as a health education tool for children's parents and families}

Objective: Describe the experience of creating a blog as a health communication tool for mothers, fathers and family caregivers of children in their first year of life. Methods: This is a descriptive, experience-based study about the development of an online health education tool. For its elaboration and development, seven stages were contemplated: situational diagnosis; literature review; elaboration and construction of the Blog; content validation; advertising and dissemination of the blog; update of posts and interaction with Internet users; analysis of participations. Results: The blog was divided into posts following the themes of breastfeeding, hygiene, vaccination, food introduction and stages of the development of the child. Conclusion: The blog favors the development of abilities for the care of the baby for contemplating information with quality, illustrations and simple language, to solve doubts through forum, to promote autonomy of the parents in the care of their baby.

Keywords: blogs; child; health education; parents.

\section{Resumen}

Uso del blog como herramienta de educación para la salud para padres y familias de niños

Objetivo: Describir la experiencia de crear un blog como herramienta de comunicación de salud para madres, padres y cuidadores familiares de niños en su primer año de vida. Métodos: Estudio descriptivo, relato de experiencia sobre el desarrollo de una herramienta de educación en salud. Para su elaboración y desarrollo se contemplaron siete etapas: diagnóstico situacional; revisión de literatura; elaboración y construcción del blog; validación de contenido; publicidad y difusión de blogs; actualización de publicaciones e interacción con usuarios de Internet; análisis de participaciones. Resultados: El blog se dividió en posts, siguiendo los temas de lactancia materna, higiene, vacunación, introducción de alimentos y etapas del desarrollo infantil. Conclusión: El blog favorece el desarrollo de habilidades para el cuidado del bebé al 
brindar información de calidad, ilustraciones y lenguaje sencillo, resolviendo dudas a través de un foro y promoviendo la autonomía de los padres en el cuidado de su bebé. Palabras-clave: blogs; niño; educación para la salud; padres.

\section{Introdução}

Em meados do século XX, após a segunda Guerra Mundial, a sociedade contemporânea passa por um processo de transição de Sociedade Industrial para a era das transformações tecnológicas, com aumento exponencial da produção e do uso de informações, bem como das Tecnologias de Informação e Comunicação (TIC) [1].

A cada ano, o acesso à internet vem se modificando, na medida em que os computadores vão perdendo espaço por contas de suas versões e formatos. Em contrapartida, além de vantagens, como banda larga móvel, o celular, de forma prática e versátil, vem ganhando cada vez mais espaço e adeptos em diferentes faixas etárias, pois além de serem multitarefas, são mais fáceis de manusear e possuem custo mais acessível à população [2]. Em função disso, o brasileiro está cada vez mais conectado a redes sociais por meio deste aparelho portátil e prático.

A partir desses levantamentos, cabe ressaltar as novas demandas criadas e incorporadas no dia a dia da sociedade para facilitar e maximizar o tempo, assim como a crescente demanda por aplicativos relacionados à área da saúde. Abre-se um leque de possibilidades para implementar ações de promoção, prevenção e cuidados a agravos a saúde. Quando comparados os custos de recursos educacionais, esse tipo de tecnologia móvel pode-se mostrar uma ferramenta bem útil, embora ainda seja preciso avaliar seu custo-benefício x custo-eficiência a longo prazo [3].

Levando-se em conta as tendências da vida moderna, procura-se, de maneira prática e inteligente, usar a internet como ferramenta para acompanhar o crescimento e desenvolvimento do bebê. Assim, por meio do blog, como um instrumento de comunicação, é possível orientar os pais desde cuidados mais simples, como o banho, até fases do desenvolvimento da criança, como o psicomotor.

O blog é uma página na Web, caracterizada como recurso pedagógico e como estratégia educativa, que deve ser atualizada frequentemente através de mensagens, "posts", que se constituem por textos e imagens [4]. Através do blog se torna possível interagir com os pais e os familiares, utilizando uma diversidade de materiais e de informações científicas para conhecimento e esclarecimento de possíveis dúvidas e comportamentos, além de proporcionar uma assistência diária e sem a necessidade de sair de casa. 
Dessa forma, compreende-se que a temática escolhida se torna de extrema relevância, principalmente no que se refere às ações de saúde voltadas para a promoção e a prevenção em saúde materna infantil, sobre os cuidados durante a gestação e a puericultura no primeiro ano de desenvolvimento da criança.

Este estudo tem como objetivo descrever a experiência da elaboração de uma ferramenta de comunicação em saúde, o blog, para mães, pais e familiares cuidadores de crianças no seu primeiro ano de vida.

\section{Métodos}

Estudo descritivo, do tipo relato de experiência de acadêmicas de enfermagem sobre a elaboração de uma ferramenta de educação em saúde online (blog) sobre promoção de saúde, prevenção de agravos e cuidados no primeiro ano de vida da criança.

O blog nomeado "O primeiro ano do bebê" foi desenvolvido por duas alunas do 5ำ período do curso de Enfermagem de uma escola privada de Belo Horizonte/MG, durante o ano de 2016, como parte do Trabalho Interdisciplinar de Graduação que abordou como tema "O uso do blog como ferramenta de comunicação na prevenção de doenças e promoção da saúde". A divulgação alcançou duas instituições de saúde de Belo Horizonte/MG, com intuito de atrair o público-alvo: mães, pais, familiares/cuidadores de crianças no primeiro ano de vida.

Para determinar o público-alvo que se planejava alcançar foram seguidas as seguintes etapas: identificação do público-alvo: a quem as informações se destinam e os canais mais apropriados para alcançá-las; determinação da mensagem; determinação do veículo: escolha do melhor meio de comunicação, que neste caso se tratou da ferramenta blogger [5].

A ferramenta de pesquisa (blog) foi elaborada na plataforma gratuita blogger e o seu processo de elaboração e desenvolvimento contemplou as seguintes etapas:

1- Etapa - diagnóstico situacional: através da prática clínica das autoras e das demandas elencadas pelos pais da criança durante a sala de espera da Unidade Básica de Saúde, observou-se a necessidade da elaboração de material educativo para esse público.

2ª Etapa - foi realizada uma revisão de literatura sobre a temática na Biblioteca Virtual Saúde em Saúde (BVS) e na Scientific Electronic Library Online (Scielo), utilizando os descritores controlados e não controlados: "aleitamento materno", "desenvolvimento do bebê", "imunização", "puericultura" e busca manual de revistas sobre a temática e manuais do Ministério da Saúde. 
$3^{\text {a }}$ Etapa - elaboração e construção da página do blog, com o endereço eletrônico: oprimeiroanodobebe.blogspot.com.br e do conteúdo das postagens realizada de forma clara e objetiva, com conteúdo fundamentado na literatura científica, apresentando linguagem acessível ao público alvo, com layout e design conforme recomendações metodológicas [6].

4를 Etapa - validação de conteúdo: A validação do conteúdo a ser postado no blog, foi realizado pelas docentes do curso que possuem experiência clínica e em pesquisa com o público-alvo. Todos os conteúdos foram avaliados e validados previamente.

5 - Etapa - publicidade e divulgação do blog para população de estudo: foram confeccionados cartões de divulgação com tamanho padrão ao cartão de visita e banners informativos divulgando o nome e o endereço eletrônico do blog, divulgação oral na sala de espera da Unidade Básica de Saúde e sala de vacinação das duas instituições de saúde de Belo Horizonte/MG e pelo canal Youtube.

6ª Etapa - atualização das postagens bem como a interação com os internautas através do fórum virtual.

7ª Etapa - análise da participação dos internautas através de dados estatísticos coletados pela plataforma blogger.

\section{Resultados}

No total, foram publicados 24 posts no período de abril a junho de 2016 . Participaram do fórum 3.806 internautas, com 13 mensagens postadas, sendo o maior público constituído por mães. O post com maior interação virtual e visitação foi referente ao depoimento de uma das integrantes do blog.

Linguagem, ilustrações, layout e design

A linguagem coloquial foi o tipo utilizado para elaboração das postagens, com vocabulários coerentes sem uso de termos científicos, favorecendo o entendimento de todos os internautas. Os textos foram estruturados, atentando para qualidade e veracidade das informações preconizadas pelo Ministério da Saúde, em acordo com manuais vigentes. Mesmo que haja limitações de leitura do público-alvo, este pode desfrutar também de vídeos elaborados, gravados e postados pelas pesquisadoras.

As ilustrações usadas enfatizam e caracterizam os conteúdos das páginas, tornando as postagens mais atrativas e agradáveis à visitação dos internautas [6]. Para 
o blog, foram selecionadas ilustrações e fotografias retiradas do Google, com boa definição, qualidade e devidamente referenciadas.

\section{O Blog "O primeiro ano do bebê"}

$\mathrm{Na}$ elaboração do conteúdo, o blog foi dividido em postagens, seguindo as temáticas elencadas pelos criadores e orientadora do projeto durante reuniões em sala de aula. Nessas postagens, foram abordados temas sobre aleitamento materno (produção de leite e seu fornecimento), higiene (tipos de banho, banho de balde e cuidados com o coto umbilical), vacinação, introdução de alimentos e etapas do desenvolvimento da criança.

\section{Discussão}

A primeira postagem foi sobre a apresentação das pesquisadoras criadoras do blog e orientadora, bem como os objetivos do projeto. A postagem "Quem somos" foi iniciada com um emocionante depoimento de uma das integrantes do blog, que, aos 19 anos de idade e 36 semanas de gestação, teve eclampsia, ficando entre a vida e a morte e, consequentemente, com a perda do filho, reconstruiu todos seus projetos. Uma História real, de angústias, medos e incertezas que aproximam os leitores e os levam a fazerem uma inflexão dos próprios problemas através dessa vivência trágica do cotidiano.

A segunda postagem do blog teve como tema "Produção do aleitamento materno" (Figura 1) e preparação do organismo da gestante. A terceira postagem abordou questões relacionadas a amamentação, como: porque amamentar; colostro, preparação do ambiente; posicionamento do bebê e da mãe (Figura 2); pega; ingurgitamento mamário, refluxos e cólicas; mamilos doloridos; benefícios da amamentação para a mãe e o bebê; e duração das mamadas.

São inúmeras as evidências sobre a importância do aleitamento materno para o desenvolvimento do bebê e em relação à diminuição da mortalidade infantil no Brasil por causas evitáveis [7]. Uma pesquisa realizada em 2020 pelo ENANI - Estudo Nacional de Alimentação e Nutrição Infantil avaliou os indicadores de aleitamento materno no Brasil e comparou com outras pesquisas de representatividade nacional, trazendo um panorama desses indicadores no decorrer de um período de 34 anos e sua evolução. Concluiu-se que a prevalência do aleitamento materno exclusivo entre crianças com idade inferior a 4 meses passou de $4,7 \%$ para $60,0 \%$ e prevalência do aleitamento materno exclusivo entre os menores de 6 meses teve um aumento de 2,9\% 
em 1986 para 45,7\% em 2020 o que corresponde a um incremento de cerca de $1,2 \%$ ao ano [7]. São dados que colaboraram para a significativa redução da mortalidade infantil no país, com a redução da taxa de óbito entre crianças menores de 5 anos de 191.505, em 1990, para 51.226, em 2015 [8].

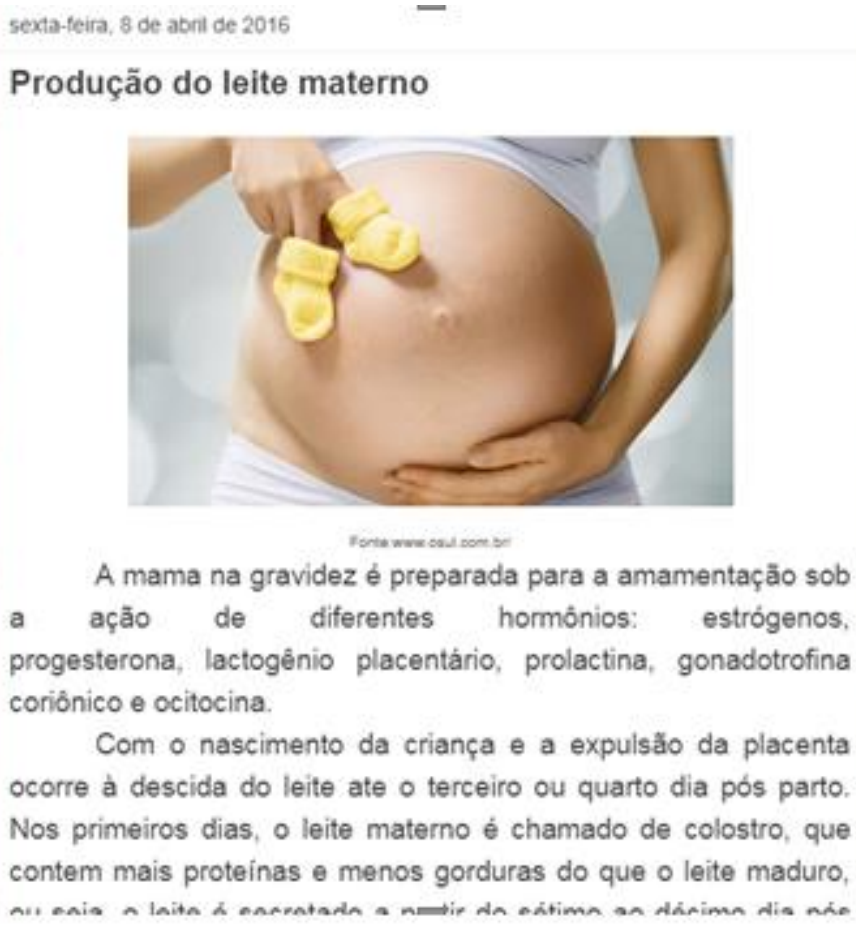

Fonte: Blog "O primeiro ano do bebê", 2018.

Figura 1 - Postagem "Produção do leite materno" do blog "O primeiro ano do bebê"

O Aleitamento Materno Exclusivo (AME) do ponto de vista nutricional é o mais adequado, por ser rico em nutrientes essenciais para o desenvolvimento e crescimento infantil, devendo ser exclusivo até os primeiros seis meses de vida e, após esse período, conjuntamente com a alimentação complementar, sendo que a continuidade da amamentação, até os dois anos de idade ou mais, é o mais recomendado [9].

Apesar de encararmos um momento de crescimento nos índices do AME no país, ainda nos deparamos com um quadro heterogênico em diferentes regiões do país. Em uma pesquisa nacional, realizada em 2008, foi encontrada uma prevalência de $41 \%$ de AME em menores de seis meses no país, com predomínio na região norte que apresentou maior prevalência dessa prática (45,9\%), seguida da região centro-oeste $(45 \%)$, sul $(43,9 \%)$ e sudeste $(39,4 \%)$, enquanto a região nordeste apresentou a pior situação (37\%) [9].

Como reflexo desses dados sobre a AME, destaca-se um estudo realizado com 50 duplas mãe/recém-nascido de uma maternidade pública do estado de São Paulo, que identificou como os principais problemas relacionados à amamentação: má posição, que dificulta a pega adequada e causa traumas mamilares, e mamadas pouco eficientes, 
resultando no não esvaziamento completo da mama, gerando baixa produção do leite e refletindo negativamente no crescimento do bebê [10].

Os enfermeiros, dotados de qualificação técnica e científica, exercem um papel fundamental diante dessa preocupante realidade, pois esses profissionais são responsáveis por elencar intervenções que busquem a melhoria desses indicadores, investindo seu tempo em educação e promoção em saúde. Uma boa prática de amamentação baseada em informação qualificada, além de uma rede de apoio sólida que inclui profissionais de saúde influencia na duração da amamentação e favorece experiências positivas para a nutriz.

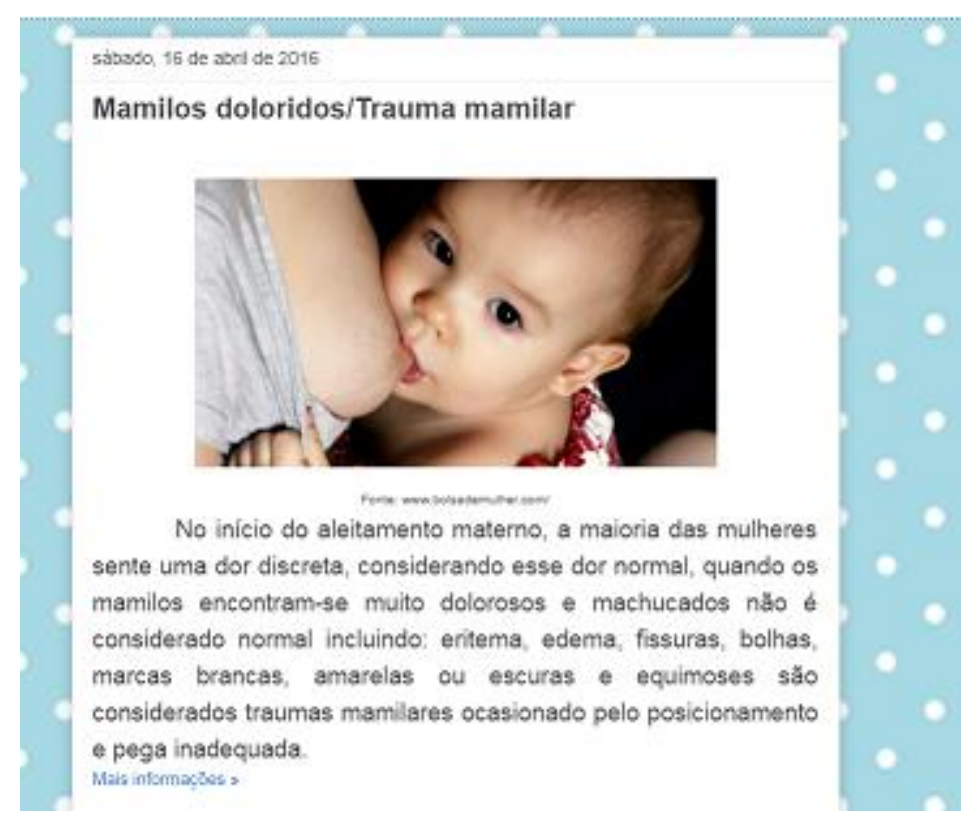

Fonte: Blog "O primeiro ano do bebê", 2018.

Figura 2 - Postagem "Amamentação: posição e pega" do blog "O primeiro ano do bebê"

A quarta postagem abordou a temática sobre refluxo gastroesofágico (RGE), que é caracterizado pelo retorno do conteúdo do estômago para o esôfago e outras áreas, como a boca. De acordo com Puccini e Berretin-Félix [11], o refluxo acomete aproximadamente $25 \%$ dos bebês, sendo o segundo maior problema de afecções mais prevalentes das doenças do trato digestivo. A irritabilidade e o choro excessivo são motivos frequentes de consulta médica do lactente com menos de três meses. É um evento comum nos primeiros meses de vida que, na maioria das vezes, não causa sintomas graves e está ligada à regurgitação, também conhecida como "golfada".

Classificado como fisiológico, funcional e patológico, o RGE mais comum entre lactentes é o fisiológico. No período pós-prandial, o esfíncter do esôfago (válvula), que faz a passagem do leite para o estômago, fica mais tempo relaxado, propiciando o retorno do alimento que foi ingerido. A alimentação e a posição também influenciam no 
RGE e esse tende a diminuir de acordo com o desenvolvimento da criança (maturidade gastrointestinal) e a ingestão de alimentos sólidos [12].

No manejo do tratamento do RGE, o mais importante é tranquilizar os pais quanto ao diagnóstico e ao tratamento, devendo o profissional de saúde ter uma compreensão ampla do ambiente e contexto familiar para as devidas orientações. Medidas simples, como elevação da cabeceira do berço, posição do bebê em decúbito dorsal, colocar o bebê para arrotar várias vezes durante a mamada, mantê-lo ereto cerca de 20 minutos e evitar usar fraldas apertadas e elásticos que pressionem o estômago, podem prevenir o RGE ou melhorar sua condição [12].

Conhecida há mais de um século, as cólicas em lactentes foi tema da quinta postagem. As cólicas se referem à dor espasmódica e abdominal aguda de início súbito, choro intenso, agudo, forte e estridente. Com frequência, ocorrem acúmulo e eliminação de gases, quando o alimento ingerido fica retido em algum ponto do intestino, não atingindo seu destino como produto da digestão. A flora intestinal age sobre a lactose, gerando os famosos gases. As partículas geradas destes gases, deslocam-se e se chocam, fazendo pressão nas alças intestinais e alterando o peristaltismo, o que irá provocar dor/cólicas [13].

Embora múltiplos fatores contribuam para o surgimento da cólica em lactentes, os profissionais de saúde podem auxiliar no cuidado direto e indireto do RN, transmitindo carinho e confiança, e contribuindo para melhor interação entre mãe e filho. Atualmente, existem vários estudos que comprovam a importância da dieta materna na redução de cólicas nos recém-nascidos, pois acredita-se que produtos industrializados, condimentados, derivados do leite de vaca, café e chocolate podem estar diretamente relacionados ao aparecimento das cólicas [13].

A sexta postagem abordou a temática sobre as etapas e tipos de banho, como preparar o banho, cuidados com o coto umbilical e banho de "ofurô". O banho se caracteriza como um momento importante na vida do bebê e, antes de iniciá-lo, devese ter em mãos todo o material necessário, como banheira, gaze, sabonete neutro, roupa, fralda limpa, toalha e água morna (temperatura corporal) [14].

O banho deve ser rápido e a temperatura ideal da água pode ser testada com o antebraço de um adulto na água. Além disso, a quantidade de água depositada na banheira deve ser moderada e a higienização deve ser iniciada pela face, pescoço, mãos e genitais. Ao término do banho, deve-se enxugar o bebê com delicadeza, principalmente nas regiões de pregas e na região perineal. A realização do curativo do coto umbilical deve ser feita logo após o banho para prevenir infecções, favorecer a cicatrização e sua mumificação [15]. 
O coto umbilical deve ser limpo e seco diariamente, com uso de cotonete ou algodão e álcool $70 \%$, em toda a volta do coto, sempre da base para ponta. Imediatamente após a limpeza, pode-se observar hiperemia transitória da pele, o que não apresenta risco de proliferação de micro-organismos. É importante que se posicione o coto umbilical acima da fralda, de forma que o local fique sempre seco [15].

A técnica do banho de ofurô (Figura 3) foi desenvolvida por uma enfermeira obstetra em 1997 na Holanda, com finalidade de relaxamento e analgesia, diminuindo os choros, as insônias e as cólicas. Consiste na imersão do bebê em um balde com água aquecida $\left(36,5\right.$ a $\left.37^{\circ} \mathrm{C}\right)$, até a altura dos ombros, em padrão flexor, simulando a sensação do útero materno [14]. Além disso, o ambiente deve ser calmo, arejado e sem luminosidade excessiva, e o procedimento pode ser realizado até o sexto mês de vida do bebê.

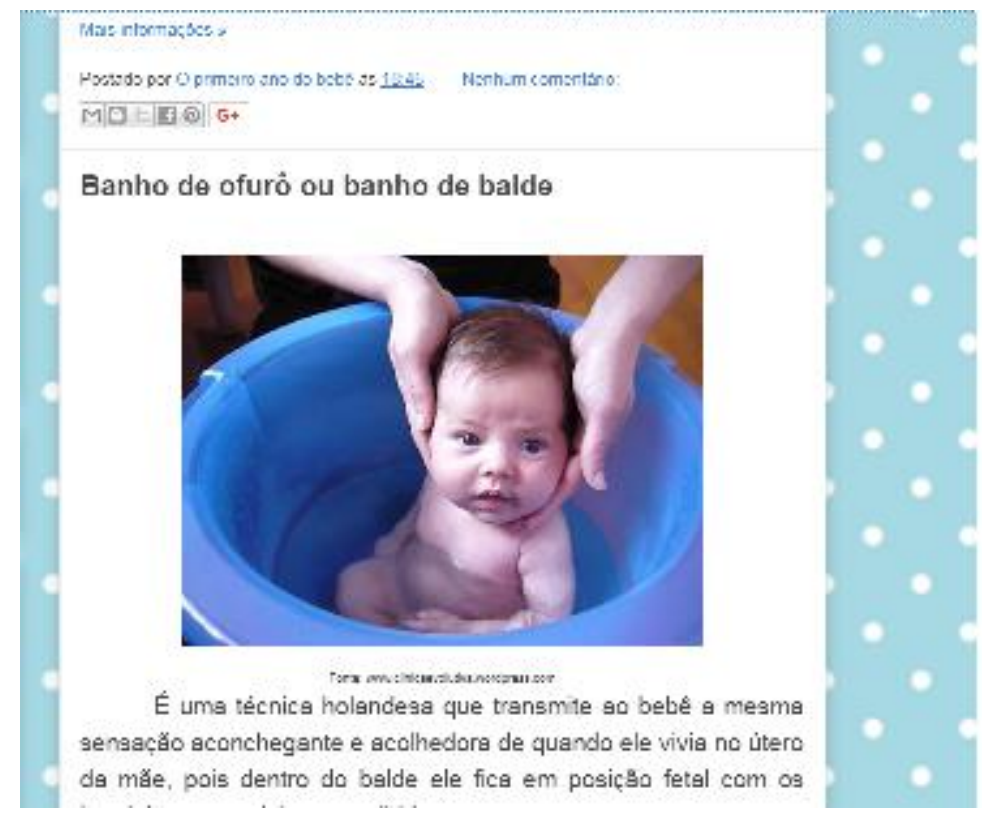

Fonte: Blog "O primeiro ano do bebê", 2018.

Figura 3 - Postagem sobre banho de ofurô ou banho de balde do blog "O primeiro ano do bebê"

A sétima postagem abordou a triagem neonatal, que é um programa de rastreamento que visa identificar distúrbios e doenças no recém-nascido. Assim, esse post apresentou assuntos relevantes como triagem auditiva (teste da orelhinha), reflexo do olho vermelho (teste do olhinho), triagem cardíaca (teste do coraçãozinho), teste do frênulo lingual (teste da linguinha), dando ênfase ao teste do pezinho.

O Teste do Pezinho (TP) faz parte do Programa Nacional de Triagem Neonatal (PNTN) e possibilita diagnóstico sobre seis patologias: fenilcetonúria, hipotireoidismo congênito, fibrose cística, hiperplasia adrenal congênita, deficiência de biotinidase e 
hemoglobinopatias [16]. O teste é realizado pelo Sistema Único de Saúde (SUS) nas unidades básica de saúde (UBS) entre o terceiro e quinto de vida do bebê. A técnica de coleta consiste na punção da região plantar do calcanhar para coletar gotas de sangue do bebê [17].

A oitava postagem abordou a imunização e o calendário vacinal de zero a 12 meses, com a finalidade de orientar os pais e cuidadores sobre as vacinas recomendadas por idade, bem como seus efeitos adversos. A vacinação é um meio de proteção de suma importância e contribui para a redução de doenças imunopreveníveis. Pensando nisso, em 1973, o Ministério da Saúde lançou o Programa Nacional de Imunizações (PNI), ofertando vacinas com objetivo de diminuir o número de hospitalizações e reduzir a mortalidade infantil [17].

O calendário de imunização está regulamentado pela Portaria № 1.498, de 19 de julho de 2013 e destaca a necessidade da administração das vacinas BCG, hepatite B, pentavalente, poliomielite, rotavírus humano, meningocócica $\mathrm{C}$, pneumocócica 10 valente, tríplice viral, tetraviral e febre amarela no primeiro ano de vida do bebê [17]. Os bebês que não estão em dia com o calendário vacinal são mais propensos a adquirir enfermidades, podendo trazer prejuízos à sua saúde, sequelas ou até mesmo o óbito.

A alimentação complementar foi o tema elencado na nona postagem. A partir do sexto mês, cerca de $70 \%$ das necessidades de ferro e zinco do lactente devem ser supridas por meio da alimentação complementar. A alimentação adequada favorece 0 crescimento, desenvolvimento e a inclusão de bons hábitos alimentares para a vida adulta, e sua deficiência poderá acarretar o aparecimento de várias patologias como anemia, desnutrição, obesidade e infecção [18].

A última postagem do blog falou sobre as etapas do desenvolvimento de zero a 12 meses para orientar os pais e cuidadores sobre desenvolvimento do bebê, de acordo com a idade e especialmente sobre suas habilidades. O desenvolvimento infantil é parte fundamental do desenvolvimento humano, principalmente no primeiro ano de vida, pois, nessa fase, são estabelecidas as capacidades sensoriais iniciais, reflexos, habilidades motoras, desenvolvimento motor, desenvolvimento cognitivo e linguagem [19].

Além disso, o desenvolvimento infantil se dá à medida que o bebê vai crescendo e se desenvolvendo, de acordo com os meios onde vive e os estímulos recebidos. Cabe aos pais e familiares esse importante papel no desenvolvimento do bebê, estimulandoo e motivando-o em cada etapa de vida. A identificação de problemas precocemente, tais como atraso na fala, alterações relacionais, dificuldade no aprendizado e agressividade, são fundamentais para uma intervenção bem-sucedida e um melhor prognóstico para essas crianças [19]. 
Conclusão

O blog favorece o desenvolvimento de habilidades para os cuidados com o bebê, por contemplar informações com qualidade, ilustrações, linguagem simples e possibilitar um ambiente seguro para sanar dúvidas promovendo a autonomia dos pais nos cuidados do seu bebê.

Esta abordagem também pode beneficiar os profissionais da saúde, pois oferece a oportunidade de reelaborar a sua forma de práticar educação em saúde. Devemos considerar que nos tempos atuais a sociedade constrói uma relação cada vez mais estreita com as plataformas digitais e precisamos nos adaptar a este novo cenário repensando formas de alcançar este público que cada vez mais busca online respostas para suas dúvidas. A interação entre profissionais e pais de forma presencial deve ser sempre valorizada, mas temos a oportunidade de atrelar mecanismos e difundir informações seguras com embasamento científico por ferramentas que geram interesse nesta geração como um blog.

O processo educativo realizado pelos enfermeiros deve ser desenvolvido de forma continuada e cabe aos profissionais procurar com afinco se familiarizar aos novos mecanismos tecnológicos que estão ao nosso alcance e podem nos auxiliar neste processo complexo de educação em saúde. O blog se mostrou uma estratégia facilitadora para o aprofundamento de conhecimentos sobre os cuidados com o bebê pelos pais e familiares, porque torna possível reforçar informações que foram passadas durante a consulta de enfermagem e trazer respostas a dúvidas que possam surgir no dia a dia.

Destaca-se, como limitação do estudo, a possível falta de acessibilidade virtual de alguns pais, seja por desconhecer ou por ter dificuldade de acesso à ferramenta, ao dispositivo eletrônico (celular) e à internet.

\section{Conflitos de interesse}

Não há conflito de interesse

Fonte de financiamento

Não há financiamento (financiamento próprio dos autores)

Contribuição de cada autor

Concepção do manuscrito: Leite AGM, Braga CDE; Coleta de dados: Leite AGM, Braga CDE; Análise e interpretação dos dados: Rosado SR; Redação do manuscrito: Leite AGM, Braga CDE, Rosado SR, Araújo CM, Dupim PEM, Cordeiro SM, Alves CGS; Validação do conteúdo do blog: Araújo CM; Revisão final: Leite AGM, Braga CDE, Rosado SR, Araújo CM, Dupim PEM, Cordeiro SM, Alves CGS 
Referências

1. Snowden A, Kolb H. Two years of unintended consequences: introducing an electronic health record system in a hospice in Scotland. J Clin Nurs 2017;26(9-10):1414-27. doi: 10.1111/jocn.13576

2. Rocha CR, Moreira APA, Silva LR, Santos IMM, Bittencourt G, Feitosa IB, Barbosa MN. A utilização das redes sociais como estratégia para continuidade da extensão universitária em tempos de pandemia. Raízes e Rumos [Internet]. 2020 [cited 2021 Oct 20];8(1):261-9.

Available

from:

http://seer.unirio.br/index.php/raizeserumos/article/viewFile/10288/9079

3. Ocde. Centro de pesquisas educacionais e inovação. Inspirados pela tecnologia, norteados pela pedagogia: uma abordagem sistêmica das inovações educacionais de base tecnológica [Internet]. Florianópolis: OCDE, 2010. [cited 2020 Out 6]. Available from: https://www.oecd.org/education/ceri/47785311.pdf

4. Czerwinski GPV, Cogo ALP. Webquest e blog como estratégias educativas em saúde escolar. Rev Gaúcha Enferm 2018;39:1-6. doi: 10.1590/1983-1447.2018.2017-0054

5. Moreira MF, Nóbrega MML, Dilva MIT. Comunicação escrita: contribuição para a elaboração de material educativo em saúde. Rev Bras Enferm 2003;56(2):184-8. doi: 10.1590/S0034-71672003000200015

6. Rosado SR, Silva NM, Filipini CB, Teles AAS, Sonobe HM, Dázio EMR. Viva bem com uma estomia: relato de experiência sobre a elaboração de uma cartilha. Rev Enferm UFPE On Line 2017;11(5):2242-9. doi: 10.5205/198-8963-v11i5a23382p2242-22492017

7. Enani. Estudo Nacional de Alimentação e Nutrição Infantil - ENANI-2019: Resultados preliminares - Indicadores de aleitamento materno no Brasil [Internet]. UFRJ: Rio de Janeiro, 2020. 9 p. [cited 2020 Out 6]. Available from: https://enani.nutricao.ufrj.br/

8. França EB, Lansky S, Rego MAS, Malta DC, França JS, Teixeira R, et al. Principais causas da mortalidade na infância no Brasil, em 1990 e 2015: estimativas do estudo de Carga Global de Doença. Rev Bras Epidemiol 2017;20(1):46-60. doi: 10.1590/19805497201700050005

9. Reis AT, Almeida LP. Enfermagem na prática materno-neonatal. $2^{\underline{a}}$ ed. Rio de Janeiro: Guanabara Koogan; 2021.

10. Siqueira FPC, Zutin TLM, Kuabara CTM, Martins TA. A capacitação dos profissionais de saúde que atuam na área do aleitamento materno. Investig Enferm Imagen Desarr 2017;19(1):171-86. doi: 10.11144/Javeriana.ie19-1.acps

11. Pavani SAL. Enfermagem pediátrica e neonatal. 1. ed. São Paulo: Manole; 2020.

12. Santos JPR, Géo LS, Braga AAP, Pereira BC, Prates CCSO, Cardoso DD, et al. Doença do Refluxo gastroesofágico em lactentes: análise global. Braz J Hea Rev 2020;3(5):14663-77. doi: 10.34119/bjhrv3n5-260

13. Guilherme JM, Vargas E, Martins GBS, Vaz CHGJ, Oliveira JF. Conhecimento das puérperas sobre a cólica no recém nascido. Rev Cient Saúde [Internet] 2020[cited 2021 
Dec 17];2(1):15-26. Available from: http://revista.urcamp.tche.br/index.php/revistasaude/article/view/3122/2424

14. Silva AC, Silva BBB, Borcades RS, Tostas JGL, Melo-Figueiredo LS, Maiworm Al, et al. Benefícios do ofurô na redução da dor em recém-nascidos pré-termo: uma revisão integrativa. Braz J Health Biomed Sci 2020;19(1):63-8. doi: 10.12957/bjhbs.2020.53534

15. Ness MJ, Davis DM, W.A. Carey WA. Neonatal skin care: a concise review. Int J Dermatol 2013;52(1):14-22. doi: 10.1111/j.1365-4632.2012.05687.x

16. Brasil. Presidência da República. Lei no 14.154, de 26 de maio de 2021, para aperfeiçoar o Programa Nacional de Triagem Neonatal (PNTN). Brasília: Presidência da República, 2021. [cited 2021 Out 20]. Available from: https://in.gov.br/web/dou/-/lei-n-14.154-de-26de-maio-de-2021-322209993

17. Goiás. Secretaria Estadual de Saúde. Superintendência de Vigilância em Saúde. Gerência de Imunização. Guia Prático de Imunização para Trabalhadores da sala de vacinação. Goiás: Secretaria Estadual de Saúde, 2021 [Internet]. [cited 2021 Out 10]. Available from: https://www.saude.go.gov.br/files/imunizacao/Guia.Pratico.Imunizacao.10ED.2021.pdf

18. Hockenberry MJ, Winkelstein W. Wong's nursing care of infants and children. 11 ed. Rio de Janeiro: Elsevier; 2018.

19. Hockenberry MJ, Winkelstein W. Wong: fundamentos de enfermagem pediátrica. $10^{\underline{a}}$ ed. Rio de Janeiro: Elsevier; 2018. 